BMJ

Open

Gastroenterology

\title{
Validity of studies suggesting postsurgical chemotherapy for resectable gastric cancer: critical appraisal of randomised trials
}

\author{
Giulia Manzini, Doris Henne-Bruns, Michael Kremer
}

To cite: Manzini G, HenneBruns D, Kremer M. Validity of studies suggesting postsurgical chemotherapy for resectable gastric cancer: critical appraisal of randomised trials. BMJ Open Gastro 2017;4:e000138. doi:10.1136/ bmjgast-2017-000138

- Additional material is published online only. To view please visit the journal online (http://dx.doi.org/10.1136/ bmjgast-2017-000138).

Received 17 February 2017 Revised 3 July 2017 Accepted 17 July 2017
Check for updates

Department of General and Visceral Surgery, Universitat Ulm, Ulm, Germany

Correspondence to Dr Giulia Manzini; giulia.manzini@yahoo.de

\begin{abstract}
Background and aim In 2013, Diaz-Nieto et al published a Cochrane review to summarise the impact of postsurgical chemotherapy versus surgery alone on survival for resectable gastric cancer. The authors concluded that postsurgical chemotherapy showed an improvement in overall survival. The aim of this article was to assess the validity of four studies included in the Cochrane review and to investigate the impact of an exclusion of these four studies on the result of the metaanalysis.

Methods Overall survival was selected as endpoint of interest. Among the 34 included papers which analysed this endpoint, we identified the four publications which have the highest weights to influence the final result. The validity of these papers was analysed using the CONSORT (Consolidated Standards of Reporting Trials) checklist for randomised controlled trials. We performed a new metaanalysis without the four studies in order to assess their impact on the general result of the original meta-analysis. Results The analysed four studies revealed several inconsistencies: inappropriate answers were found in up to $77 \%$ of the items of the CONSORT checklist. Unclear or inadequate randomisation, missing blinded set-up, conflict of interest and lacking intention-to-treat analysis were the most common findings. When performing a metaanalysis excluding the four criticised studies, postsurgical chemotherapy still showed a significant improvement in overall survival. Even when excluding all single studies with a statistically significant outcome by themselves and performing a meta-analysis on the remaining 26 studies, the result remains statistically significant.

Conclusion The four most powerful publications in the Cochrane review show substantial deficits. We suggest a more critical appraisal regarding the validity of single studies. However, after the exclusion of these four studies, the result of the meta-analysis did not change.
\end{abstract}

\section{INTRODUCTION}

Despite declines, gastric cancer is still the fifth most common malignancy in the world after lung, breast, colorectum and prostate cancer. ${ }^{1}$ Although surgery is considered the only curative option, ${ }^{2}$ the role of adjuvant chemotherapy (CTx) after curative resection in improving patients' survival remains
Summary box

What is already known about this subject?

- Following the results of a Cochrane review by Diaz-Nieto et al. 2013, post-surgical chemotherapy should be used for patients with resectable gastric cancer.

What are the new findings?

- The validity of the four most powerful studies included is not sufficient for inclusion in a metaanalysis.

- However, even when those four studies are excluded, the overall results of the Cochrane review do not change.

How might it impact on clinical practice in the foreseeable future?

- A more critical appraisal regarding the validity of single studies is warranted.

- The literature needs to be reassessed in detail in order to avoid unnecessary side effects for the patients as well as unnecessary costs for the health care systems.

controversial. $^{3}$ While some trials support the use of adjuvant 5-fluorouracil (5-FU) combination CTx,${ }^{45}$ others do not show any positive effect. ${ }^{67}$ Several meta-analyses have attempted to address the validity of adjuvant CTx in this setting with the majority failing to confirm a positive association due in large part to a lack of sufficient evidence. ${ }^{8}{ }^{9}$ In 2013, Diaz-Nieto et al published a Cochrane review investigating the impact of postsurgical CTx versus surgery alone for resectable gastric cancer on overall survival (OS). ${ }^{3}$ The authors identified 34 randomised controlled trials (RCT) reporting OS and 15 reporting disease-free survival (DFS) and concluded that postsurgical CTx showed an improvement in OS (HR $0.85 ; 95 \%$ CI $(0.80 ; 0.90))$ as well as in DFS (HR 0.79; $95 \%$ CI $(0.72 ; 0.87)$ ). Although all trials had a high risk of bias and 
the authors assessed risks such as sequence generation, allocation concealment, blinding, incomplete outcome data, selective outcome reporting, baseline imbalance, early stopping, and source of funding bias according to published recommendations, ${ }^{10-13}$ several studies with questionable validity were included in the Cochrane review.

For quite a while now, a more individualised therapeutic approach instead of a standardised treatment has increasingly been discussed with respect to patients with malignant tumours. The new 'choosing wisely' campaign also contributes to deciding carefully among treatment modalities with their potential side effects. Therefore, due to the validity of the underlying studies, to us it seemed necessary to re-evaluate treatment recommendations for special tumour entities.

Thus, the aim of this work was to assess the validity of four of the studies included in the meta-analysis of DiazNieto $e t a l^{3}$ which confirmed the benefit of postoperative 5-FU combination CTx in gastric cancer with the intention to invite everyone to critically interpret the results and the methodology by which the results were achieved.

\section{MATERIALS AND METHODS}

The meta-analysis of Diaz-Nieto et $a l^{3}$ included a total of 34 studies. Eight studies (24\%) (Neri et $a l^{14}$, Sakuramoto $e t a l^{15}$, Fujimoto $e t a l^{16}$, Douglass $e t a l^{17}$, Chou et $a l^{18}$, Cirera $e t a l^{19}$, Grau et $a l^{20}$, Nakajima $e t a l^{21}$ ) found a statistically significant advantage in survival in patients undergoing adjuvant CTx after curative surgery compared with patients receiving only surgical resection $(\mathrm{HR}<1$ with significant $95 \%$ CI not including 1 ). All the other 26 studies $(76 \%)$ were not statistically significant: five of them had an HR $>1$ and the other 21 studies only found a trend for a better survival after adjuvant CTx $(\mathrm{HR}<1)$.

In the first part of the Results section, we assessed the validity of the four most powerful studies included in the Cochrane review of Diaz-Nieto $e t a \vec{l}^{3}$ which found a statistically significant advantage in survival in patients receiving postsurgical CTx after curative resection for gastric cancer compared with patients undergoing surgery only. These studies are those of Sakuramoto, Neri, Fujimoto, and Douglass. The assigned weights are $4.4 \%, 3.8 \%, 2.6 \%$, and $2.9 \%$, respectively.

In the second part of the Results section, we performed a new meta-analysis without these aforementioned four studies, and finally we present the results of the meta-analysis with all eight statistically significant studies confirming the survival advantage for patients treated with postsurgical CTx excluded. In this last case, only statistically non-significant studies were included in the meta-analysis.

\section{Selection of the studies and assessment of their validity}

To analyse the validity of the Cochrane review, one has to select a positive statement of this review because only in case of a positive statement specific data can be identified



Systematic Review (endpoints: overall survival, disease free survival, quality of life)


Selection of the 4 studies [14-17] with the highest power to support the positive result

Figure 1 Four steps to the analysis of validity of a systematic review. We identified the endpoint of interest (overall survival) and selected the four most powerful studies addressing this endpoint on the basis of the assigned weights from the authors of the systematic review as these studies contributed essentially to the positive result of the systematic review. We finally assessed the validity of these studies by using the CONSORT checklist. CONSORT, Consolidated Standards of Reporting Trial.

for an assessment of validity. In case of negative results, there are too many possibilities that could lead to negative results. From the several endpoints investigated in the Cochrane review of Diaz-Nieto et al, ${ }^{3}$ we identified OS as a major endpoint of interest. Among the 34 studies identified by the authors of the Cochrane review investigating OS, we selected the four most powerful studies as weighted by the authors of the review which support the advantage of postsurgical 5-FU-based CTx: Neri et $\mathrm{al}^{14}{ }^{14}$ Sakuramoto et $a l^{15}$, Fujimoto $e t a l^{6}$, and Douglass et $a l^{17}$. The weights assigned to these four studies by the authors of the systematic review according to their sample size, precision of the estimates and width of the CIs were 3.8\%, $4.4 \%, 2.6 \%$, and $2.9 \%$, respectively. We then assessed the validity of these studies using the CONSORT (Consolidated Standards of Reporting Trials) checklist, ${ }^{22}$ which is a validated instrument for the evaluation of RCT and which has a total of 37 items. The checklist with all items and their precise description is available in the online supplementary appendix 1 . We then asked whether the positive result in the Cochrane review is supported by sufficient validity. Figure 1 illustrates our methodology. Two independent review authors (GM and MK) assessed the validity of each of the four publications.

\section{Meta-analysis}

We repeated the meta-analysis using $\mathrm{R}$ without the four analysed studies $(\mathrm{n}=30)$ and compared the result with 
Table 1 Summary of the four analysed studies

\begin{tabular}{lllll}
\hline Study (year) & Neri et al $^{\mathbf{1 4}}$ & Sakuramoto et al & Fujimoto et al $^{\mathbf{1 6}}$ & Douglass et al $^{\mathbf{1 7}}$ \\
\hline $\begin{array}{l}\text { Number of included } \\
\text { patients (intervention }\end{array}$ & 69 vs 68 & 529 vs 530 & 129 vs 120 & 71 vs 71 \\
vs control) & & &
\end{tabular}

Inclusion criteria
Resected, node- $\quad$ Ro resected,

positive gastric cancer, node positive (D2

no distant metastases or more extensive

lymph node dissection),

no distant metastases,

no neoadjuvant CTx
Resected gastric Resected stomach cancer

cancer, no neoadjuvant or cancer at the gastro-

and intraoperative CTx oesophageal junction,

complete recovery from

surgery, ingestion of a solid diet, maintenance of weight and absence of infection, no distant metastasis (directed extension of the neoplasm was accepted)

\begin{tabular}{|c|c|c|c|c|}
\hline Intervention group & $\begin{array}{l}\text { Postsurgical CTx } \\
\text { with epidoxorubicin, } \\
\text { leucovorin and 5-FU }\end{array}$ & $\begin{array}{l}\text { Postsurgical CTx } \\
\text { with S-1, an oral } \\
\text { fluoropyrimidine }\end{array}$ & $\begin{array}{l}\text { Postsurgical CTx with } \\
5-\mathrm{FU} \text { and FT-207, a } \\
\text { derivate of } 5-\mathrm{FU}\end{array}$ & $\begin{array}{l}\text { Postsurgical CTx using } \\
\text { 5-FU and methyl-CCNU }\end{array}$ \\
\hline Control group & No treatment & No treatment & No treatment & No treatment \\
\hline $\begin{array}{l}\text { Outcome } \\
\text { (intervention vs } \\
\text { control) }\end{array}$ & $\begin{array}{l}\text { Median survival time } \\
\text { ( } 31 \text { months (range } \\
7 \text { to } 60+\text { ) vs } 18 \text { months } \\
\text { (range } 2 \text { to } 60+\text { ), } \\
p<0.01 \text { ) }\end{array}$ & $\begin{array}{l}\text { HR for death } 0.68 \\
\text { (95\% Cl } 0.52 \text { to } 0.87 \text {, } \\
\mathrm{p}=0.003) .3 \text {-year overall } \\
\text { survival rate } 80.1 \% \\
\text { (95\% } \mathrm{Cl} 76.1 \text { to } 84.0) \\
\text { vs } 70.1 \%(95 \% \mathrm{Cl} 65.5 \\
\text { to } 74.6)\end{array}$ & $\begin{array}{l}\text { Higher survival rates } \\
\text { for intervention }\left(\chi^{2} \text { at }\right. \\
24 \text { and } 36 \text { months, } \\
p<0.05 \text { and } p<0.1 \text {, } \\
\text { respectively) }\end{array}$ & $\begin{array}{l}29 \text { deaths vs } 40 \text { deaths. } \\
\text { Log-rank testing of the two } \\
\text { survival patterns revealed a } \\
p \text { value of } 0.06 \text {. Covariate } \\
\text { analysis increased the value } \\
\text { of this test to a level of } \\
\text { significance, } p<0.03 .50 \text { th } \\
\text { percentile at } 56 \text { months } \\
\text { vs median survival at } \\
33 \text { months }\end{array}$ \\
\hline
\end{tabular}

the Cochrane review

(\%)

5-FU, 5-fluorouracil; CTx, chemotherapy.

the original meta-analysis comprising 34 studies. In a next step, we assumed that all single studies with a statistically significant benefit of postoperative CTx after curative resection of gastric cancer $(n=8)$ were not valid enough and performed a second meta-analysis with the remaining 26 studies. The results were compared with the original meta-analysis $(n=34$ studies $)$. The meta-analyses were performed with R, V.3.2.0, with the package 'meta' (http://www.r-project.org/foundation).

\section{RESULTS}

\section{Assessment of the validity of the studies}

Table 1 presents a summary of the four analysed papers. The results are reported for each of the four included studies.

Table 2 summarises all the items present in the CONSORT checklist showing how the studies deal with them (extended table can be found in the online supplementary file 2).

In this section, we describe the problems of each study. Regarding the study by Neri et $a l^{14}, 18$ of the 32 validity criteria $(56 \%)$ were not met. Five items were not applicable. The patients included were stratified by centre but not randomly assigned to the control or intervention group, therefore we cannot recommend the use of this design in a confirmatory study. Inclusion of untreated controls limits the interpretation of the study. Specifically, the difference between the intervention and control group may be caused by a non-specific effect such as a placebo effect. The risk profiles of the two groups are different with a high probability of unbalanced risk distribution in favour of the intervention group. It is also unclear whether the allocation to the study group was concealed as information about the randomisation procedure is not included. Moreover, blinding was not possible as the control group did not receive any treatment. Furthermore, it is unclear whether all patients were included in the results because table 1 reports only evaluable patients. No information about the number of randomised patients is given. An intention-to-treat (ITT) analysis is not explicitly described. The definition of the study as 'randomized' in the title of the article implies a researcher bias. Taken together, these issues lead to insufficient validity of the report and thus the described effect cannot be considered as clinically relevant. 
Table 2 Assessment of validity of the analysed studies according to the CONSORT checklist ${ }^{18}$

\begin{tabular}{|c|c|c|c|c|c|}
\hline Section/topic & Item number & Neri et $a l^{14}$ & Sakuramoto et al ${ }^{15}$ & Fujimoto et $a I^{16}$ & Douglass et $\mathrm{al}^{17}$ \\
\hline \multicolumn{6}{|l|}{$\begin{array}{l}\text { Title and } \\
\text { abstract }\end{array}$} \\
\hline & $1 a$ & Yes & No & No & No \\
\hline & $1 b$ & No & Yes & No & No \\
\hline \multicolumn{6}{|l|}{ Introduction } \\
\hline \multirow[t]{2}{*}{ Background and objectives } & $2 a$ & Yes & Yes & Yes & Yes \\
\hline & $2 b$ & Yes & Yes & Yes & Yes \\
\hline \multicolumn{6}{|l|}{ Methods } \\
\hline \multirow[t]{2}{*}{ Trial design } & $3 a$ & No & Yes & No & No \\
\hline & $3 b$ & Not applicable & Yes & No & No \\
\hline \multirow[t]{2}{*}{ Participants } & $4 a$ & Yes & Yes & Yes & Yes \\
\hline & $4 b$ & Yes & Yes & No & No \\
\hline Interventions & 5 & Yes & Yes & Yes & Yes \\
\hline \multirow[t]{2}{*}{ Outcomes } & $6 a$ & Yes & Yes & Yes & Yes \\
\hline & $6 b$ & Not applicable & Not applicable & Not applicable & Not applicable \\
\hline \multirow[t]{2}{*}{ Sample size } & $7 a$ & No & Yes & No & No \\
\hline & $7 b$ & No & Yes & Not applicable & Not applicable \\
\hline \multirow[t]{4}{*}{ Randomisation } & $8 a$ & No & Yes & No & No \\
\hline & $8 b$ & No & No & No & No \\
\hline & 9 & No & No & No & No \\
\hline & 10 & No & No & No & No \\
\hline \multirow[t]{2}{*}{ Blinding } & $11 a$ & No & No & No & No \\
\hline & $11 b$ & Yes & Yes & No & Yes \\
\hline \multirow[t]{2}{*}{ Statistical methods } & $12 a$ & Yes & Yes & No & Yes \\
\hline & $12 b$ & Not applicable & Not applicable & No & No \\
\hline \multicolumn{6}{|l|}{ Results } \\
\hline \multirow[t]{2}{*}{ Participant flow } & $13 a$ & No & Yes & No & No \\
\hline & $13 b$ & No. Same as $13 a$ & Yes & No & No \\
\hline \multirow[t]{2}{*}{ Recruitment } & $14 a$ & $\begin{array}{l}\text { Yes (previous } \\
\text { publication) }\end{array}$ & Yes & No & Yes \\
\hline & $14 b$ & No & Yes & No & No \\
\hline Baseline data & 15 & Yes & Yes & No & Yes \\
\hline Numbers analysed & 16 & No & Yes & No & No \\
\hline \multirow[t]{2}{*}{ Outcomes and estimation } & $17 a$ & Yes & Yes & No & Yes \\
\hline & $17 b$ & Not applicable & Yes & Yes & Not applicable \\
\hline Ancillary analysis & 18 & Not applicable & Yes & No & No \\
\hline Harms & 19 & No & Yes & Yes & Yes \\
\hline \multicolumn{6}{|l|}{ Discussion } \\
\hline Limitations & 20 & No & No & No & Yes \\
\hline Generalisability & 21 & No & Yes & No & No \\
\hline Interpretation & 22 & Yes & Yes & Yes & Yes \\
\hline \multicolumn{6}{|l|}{ Other information } \\
\hline Registration & 23 & No & Yes & No & No \\
\hline Protocol & 24 & No & No & No & No \\
\hline Funding & 25 & No & No & No & No \\
\hline
\end{tabular}

CONSORT, Consolidated Standards of Reporting Trials. 
In the study of Sakuramoto $e t a l^{15}$, we identified poor validity in 7 of the 35 validity criteria (20\%). Two items were not applicable. Again, as in the previous study, the use of untreated controls limits the interpretation of the study. Additionally, different follow-up modalities are described for the control and intervention group which could be a source of bias. Patients in the intervention group underwent haematological tests and assessments of clinical symptoms every 2 weeks while patients in the control group underwent similar examinations only every 3 months. Due to the use of the minimisation method, allocation concealment is not maintained. Blinding was not possible in this work either as the control group did not receive any treatment. Results are influenced by conflicting interests because a sponsor was involved in the design of the trial and collection of data. As the validity of the report is not sufficient, the described effect cannot be considered as clinically relevant.

In the study of Fujimoto et al, ${ }^{16} 27$ of the 35 validity criteria were not met (77\%). Two items were not applicable. It is unclear whether or not the study was randomised because no randomisation method is described. Again, the use of untreated controls limits the interpretation of the study. The risk profiles of the two groups were not reported and therefore it is not possible to check whether the risk distribution is balanced. It is unclear whether the allocation to the study group was concealed because information about the randomisation procedure is missing. Blinding was not possible as the control group did not receive any treatment. From the 129 patients included in the intervention group, only 97 were analysed (75\%), resulting in a loss of power. An ITT analysis was not performed. As the validity of the report is not sufficient, the described effect cannot be considered as clinically relevant.

In the fourth study (Douglass et $a l^{17}$ ), 21 of the 34 validity criteria were not met $(62 \%)$. Three items were not applicable to this study. The randomisation process is not described in detail. Again, the use of untreated controls limits the interpretation of the study. It is unclear whether the allocation to the study group was concealed because information about the randomisation procedure is missing. Blinding was not possible as the control group did not receive any treatment. After the closure of the recruitment phase, 23 patients were withdrawn from the study by a committee and by the principal investigator resulting in a loss of power. The reasons for the withdrawal are not explained in detail so that a conflict of interest cannot be excluded. Moreover, the authors of this last analysed publication state that an update of the results is necessary in order to confirm these results. We could not find a published update in PubMed. As the validity of the report is not sufficient, the described effect cannot be considered as clinically relevant.

\section{Meta-analyses}

Figure 2 shows the result of the meta-analysis when the four analysed studies were excluded. A total of 30 studies were included. Four studies (Chou et al, ${ }^{18}$ Cirera et $a l,{ }^{19}$ Grau $e t a l,{ }^{20}$ and Nakajima $\left.e t a l^{21}\right)$ showed a positive and statistically significant result in favour of the use of postsurgical CTx after curative resection for gastric cancer. Twenty-six of the included studies were not statistically significant by themselves. The new meta-analysis estimate had an HR of 0.88 with a $95 \%$ CI (0.83 to 0.94$)$. The estimate of the original meta-analysis was 0.85 with $95 \% \mathrm{CI}$ (0.80 to 0.90$)$. The exclusion of the four studies did not significantly change the result of the meta-analysis.

We then performed a second meta-analysis (figure 3) excluding the other four studies which found a positive and statistically significant result as well. After the exclusion of all eight studies with positive and statistically significant results, the new meta-analysis consisted only of 26 statistically non-significant studies ( 5 with an $\mathrm{HR}>1$ and 21 with an $\mathrm{HR}<1)$. The new meta-analysis estimate (HR $0.92,95 \%$ CI (0.86 to 0.97$)$ ) was slightly higher than the original one, but still statistically significant, indicating a better survival in patients receiving adjuvant CTx after curative resection for gastric cancer compared with patients undergoing surgery only.

\section{DISCUSSION}

In the present manuscript, we assessed the validity of four studies included in the meta-analysis of Diaz-Nieto et $a l^{3}$ which supports the results of improved survival in patients treated with postsurgical CTx after curative resection for gastric cancer. However, it is important to identify possible bias in the four studies which support the result of the meta-analysis, because bias jeopardises validity. We demonstrated that these four studies are not valid enough to be included in a Cochrane review. Nevertheless, even when excluded from the meta-analysis, the overall result of the meta-analysis still confirms improved survival by the administration of adjuvant CTx after curative surgery. Furthermore, by excluding all single studies that show a significant benefit of adjuvant CTx and performing a new meta-analysis on the remaining 26 single studies, which by themselves were not statistically significant, the original finding of a benefit of adjuvant CTx after surgery to our surprise prevails.

We will first illustrate the problems we discovered in the four mathematically most influential studies supporting the conclusions and, in a second step, discuss our findings after performing the new meta-analyses.

\section{Common problems in all studies}

We agree with the authors of the meta-analysis ${ }^{3}$ that the lack of a placebo-controlled and blinded study affects the validity of the three studies and consequently the validity of the review. Without placebo control, it is impossible to differentiate between specific pharmacological and placebo effects. Placebo effect is defined as the 'response of a subject to a substance or any procedure known to be without specific therapeutic effect for the condition being 
Study

$\begin{array}{lcc}\text { Allum 1989 } & 141 & 130 \\ \text { Bajetta 2002 } & 135 & 136 \\ \text { Bonfanti 1988 } & 75 & 69 \\ \text { Bouche'2005 } & 127 & 133 \\ \text { Chipponi 2004 } & 93 & 103 \\ \text { Chou 1994 } & 59 & 56 \\ \text { Cirera 1999 } & 76 & 72 \\ \text { Coombes 1990 } & 133 & 148 \\ \text { De Vitta 2007 } & 112 & 113 \\ \text { Di Costanzo 2008 } & 130 & 128 \\ \text { Engstrom 1985 } & 91 & 89 \\ \text { Fielding 1983 } & 141 & 130 \\ \text { Grau 1993 } & 68 & 66 \\ \text { Hallissey 1994 } & 138 & 145 \\ \text { Higgins 1983 } & 66 & 68 \\ \text { Huguier 1980 } & 27 & 26 \\ \text { Kim 1992 } & 77 & 94 \\ \text { Krook 1991 } & 61 & 64 \\ \text { Kulig 2010 } & 101 & 154 \\ \text { Lise 1995 } & 155 & 159 \\ \text { Macdonald 1995 } & 93 & 100 \\ \text { Nakajima 1999 } & 288 & 285 \\ \text { Nakajima 2007 } & 93 & 95 \\ \text { Nashimoto 2003 } & 127 & 123 \\ \text { Nitti 2006 EORTC } & 103 & 103 \\ \text { Nitti 2006 ICGC } & 91 & 100 \\ \text { Ochiai 1983 } & 49 & 40 \\ \text { Popiela 1982 } & 16 & 44 \\ \text { Popiela 2004 } & 53 & 52 \\ \text { Tentes 2006 } & 20 & 20 \\ & & \end{array}$

\section{Fixed effect model} Random effects model
$\mathbf{N}(\mathrm{T}) \mathbf{N}(\mathrm{C}) \quad$ Hazard Ratio

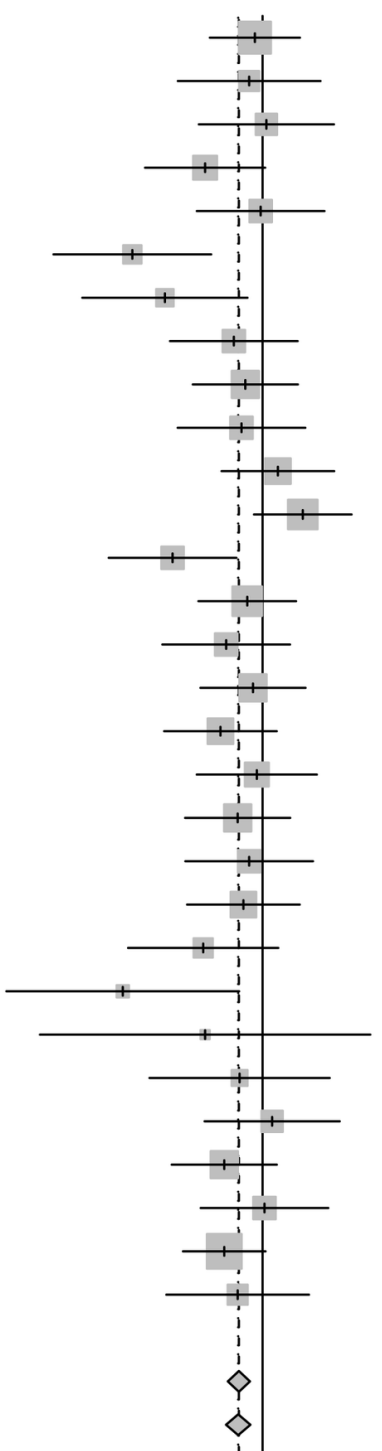

HR

$95 \%-\mathrm{Cl} W($ fixed)

$W($ random)

$0.93[0.64 ; 1.35]$

$6.1 \%$

$5.5 \%$

$1.02[0.72 ; 1.45]$

$2.4 \%$

$2.6 \%$

$2.7 \%$

$2.8 \%$

$0.74[0.54 ; 1.01]$

$3.4 \%$

$3.5 \%$

$3.1 \%$

$2.2 \%$

$0.51[0.34 ; 0.76]$

$3.0 \%$

$2.0 \%$

$2.0 \%$

$0.60 \quad[0.39 ; 0.92]$

$1.8 \%$

$3.0 \%$

$3.1 \%$

$0.91[0.69 ; 1.20]$

$4.4 \%$

$4.3 \%$

$0.90[0.64 ; 1.25]$

$3.0 \%$

$3.9 \%$

$3.1 \%$

$3.9 \%$

$1.23[0.96 ; 1.59]$

$5.2 \%$

$3.0 \%$

$5.2 \%$

$3.0 \%$

$4.4 \%$

$3.9 \%$

$3.4 \%$

$4.4 \%$

$3.0 \%$

$3.9 \%$

$2.2 \%$

$0.9 \%$

$0.5 \%$

$1.5 \%$

$2.7 \%$

$4.4 \%$

$3.0 \%$

$7.2 \%$

$2.4 \%$

$4.9 \%$

$3.1 \%$

$4.9 \%$

$3.1 \%$

$4.3 \%$

$3.9 \%$

$3.5 \%$

$4.3 \%$

$3.1 \%$

$3.9 \%$

$2.4 \%$

$1.0 \%$

$0.5 \%$

$1.7 \%$

$2.8 \%$

$4.3 \%$

$3.1 \%$

$6.3 \%$

$2.6 \%$

$0.88[0.83 ; 0.94] \quad 100 \%$

$0.88[0.83 ; 0.94]$

Heterogeneity: I-squared=15.3\%, tau-squared $=0.0048, p=0.2304$



Favours T Favours C

Figure 2 Meta-analysis of $n=30$ studies after the exclusion of the four analysed studies. $N(C)$, number of patients in the control group; $\mathrm{N}(\mathrm{T})$, number of patients in the experimental group; W(fixed), weight assigned to the study by using a fixed effect model; $W($ random), weight assigned to the study by using a random effect model.

treated'. ${ }^{23}$ Several studies demonstrated that perceptual characteristics of drugs ${ }^{24}$ the route of administration, ${ }^{25}$ laboratory tests, ${ }^{26}$ diagnosis,${ }^{27}$ and doctor-patient relationship play an important role in the outcome of illness. ${ }^{28-31}$ Information regarding treatment or no treatment alone is sufficient to cause a placebo effect. ${ }^{32}$ Moreover, patients and doctors' preferences could also have influenced the results in an open study. ${ }^{33}$ Patients assigned to the control group feel disadvantaged because they expect to be treated. Furthermore, when there is no concealment of treatment allocation, the randomisation procedure is compromised because of conscious or subconscious bias. ${ }^{34}$ It is important to perform an
ITT analysis to maintain the balance distribution of risk factors between groups which is achieved by a randomisation procedure. Only in the study of Sakuramoto $e t a l^{15}$ that a correct ITT analysis was conducted. Collectively, these aspects affect the validity of the reports and therefore the described effects cannot be considered as clinically relevant.

\section{Specific problems of the study by Neri et al ${ }^{4}$}

This study is the final report of a previously published study by Neri $e t a l^{35} 35$ in which patients were stratified by centre to receive either CTx or were in the control group at follow-up. It is not clear whether the centres were 
Study

$\begin{array}{lcc}\text { Allum 1989 } & 141 & 130 \\ \text { Bajetta 2002 } & 135 & 136 \\ \text { Bonfanti 1988 } & 75 & 69 \\ \text { Bouche'2005 } & 127 & 133 \\ \text { Chipponi 2004 } & 93 & 103 \\ \text { Coombes 1990 } & 133 & 148 \\ \text { De Vitta 2007 } & 112 & 113 \\ \text { Di Costanzo 2008 } & 130 & 128 \\ \text { Engstrom 1985 } & 91 & 89 \\ \text { Fielding 1983 } & 141 & 130 \\ \text { Hallissey 1994 } & 138 & 145 \\ \text { Higgins 1983 } & 66 & 68 \\ \text { Huguier 1980 } & 27 & 26 \\ \text { Kim 1992 } & 77 & 94 \\ \text { Krook 1991 } & 61 & 64 \\ \text { Kulig 2010 } & 101 & 154 \\ \text { Lise 1995 } & 155 & 159 \\ \text { Macdonald 1995 } & 93 & 100 \\ \text { Nakajima 1999 } & 288 & 285 \\ \text { Nashimoto 2003 } & 127 & 123 \\ \text { Nitti 2006 EORTC } & 103 & 103 \\ \text { Nitti 2006 ICGC } & 91 & 100 \\ \text { Ochiai 1983 } & 49 & 40 \\ \text { Popiela 1982 } & 16 & 44 \\ \text { Popiela 2004 } & 53 & 52 \\ \text { Tentes 2006 } & 20 & 20\end{array}$

Fixed effect model Random effects model

\section{Heterogeneity: I-squared $0 \%$,}

$\mathbf{N}(T) \mathbf{N}(\mathrm{C}) \quad$ Hazard Ratio

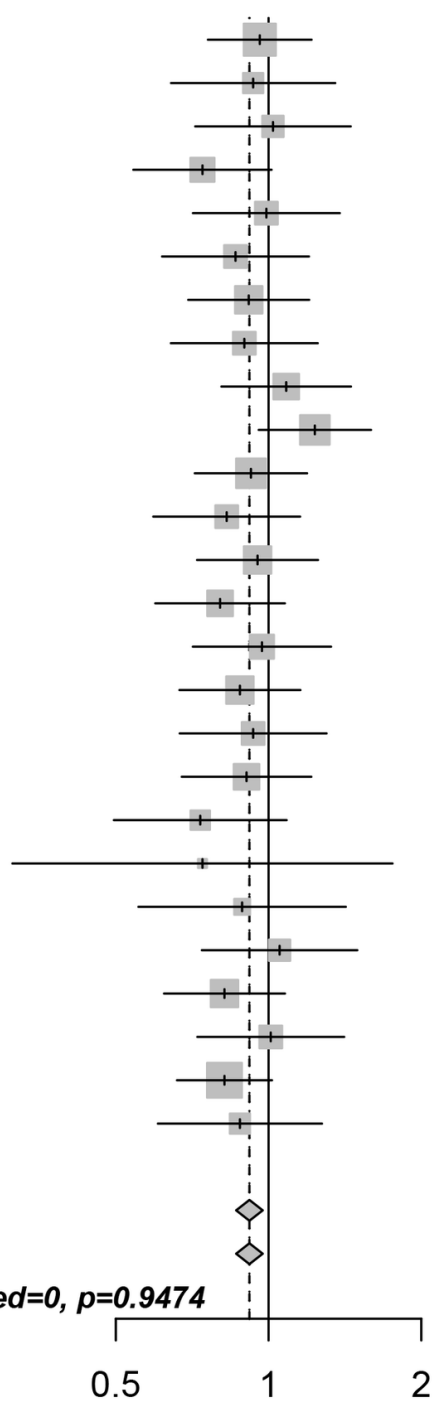

Favours $\mathrm{T}$ Favours $\mathrm{C}$
HR $\quad 95 \%-C l$ W(fixed) $W($ random)

$\begin{array}{llll}0.96[0.76 ; 1.22] & 6.6 \% & 6.6 \% \\ 0.93[0.64 ; 1.35] & 2.6 \% & 2.6 \% \\ 1.02[0.72 ; 1.45] & 2.9 \% & 2.9 \% \\ 0.74[0.54 ; 1.01] & 3.7 \% & 3.7 \% \\ 0.99[0.71 ; 1.38] & 3.3 \% & 3.3 \% \\ 0.86[0.62 ; 1.20] & 3.3 \% & 3.3 \% \\ 0.91[0.69 ; 1.20] & 4.8 \% & 4.8 \% \\ 0.90[0.64 ; 1.25] & 3.3 \% & 3.3 \% \\ 1.08[0.81 ; 1.45] & 4.2 \% & 4.2 \% \\ 1.23[0.96 ; 1.59] & 5.6 \% & 5.6 \% \\ 0.92[0.72 ; 1.19] & 5.6 \% & 5.6 \% \\ 0.83[0.59 ; 1.15] & 3.3 \% & 3.3 \% \\ 0.95[0.72 ; 1.25] & 4.8 \% & 4.8 \% \\ 0.80[0.60 ; 1.08] & 4.2 \% & 4.2 \% \\ 0.97[0.71 ; 1.33] & 3.7 \% & 3.7 \% \\ 0.88[0.67 ; 1.16] & 4.8 \% & 4.8 \% \\ 0.93[0.67 ; 1.30] & 3.3 \% & 3.3 \% \\ 0.90[0.67 ; 1.21] & 4.2 \% & 4.2 \% \\ 0.73[0.50 ; 1.09] & 2.4 \% & 2.4 \% \\ 0.74[0.31 ; 1.75] & 0.5 \% & 0.5 \% \\ 0.89[0.55 ; 1.42] & 1.6 \% & 1.6 \% \\ 1.05[0.74 ; 1.50] & 2.9 \% & 2.9 \% \\ 0.82[0.62 ; 1.08] & 4.8 \% & 4.8 \% \\ 1.01[0.72 ; 1.41] & 3.3 \% & 3.3 \% \\ 0.82[0.66 ; 1.02] & 7.8 \% & 7.8 \% \\ 0.88[0.61 ; 1.27] & 2.6 \% & 2.6 \% \\ 0.92[0.86 ; 0.97] & 100 \% & \\ 0.92[0.86 ; 0.97] & -- & 100 \%\end{array}$

determined by evaluating the potential covariate imbalance that would result if he or she were assigned to the treatment or likewise to the control group. ${ }^{40}$ Minimisation aims at achieving balance over a large number of prespecified prognostic factors simultaneously. In contrast to the opinion of the authors of the Cochrane review, ${ }^{3}$ we raise concerns over this design as it compromises adequate generation of an allocation sequence and concealment in this study. In fact, investigators using minimisation can determine the group to which a prospective subject would be allocated and then decide whether this is positive or negative in terms of creating an imbalance in some key predictor of outcome not considered in the imbalance function. Despite adding randomisation, so that the treatment that minimises the imbalance function for a given patient is not necessarily allocated to
Specific problems of the study by Sakuramoto et al ${ }^{15}$

In the study of Sakuramoto $\mathrm{et} a l,{ }^{15}$ a minimisation method is used. Minimisation, ${ }^{36-39}$ a type of dynamic allocation, is gaining popularity especially in clinical cancer trials. In this design, the new subject's treatment assignment is 
that patient, there is a high probability of this being the case. $^{41}$ The European Medicines Agency's committee ${ }^{42}$ states that 'dynamic allocation is strongly discouraged.' Regarding follow-up modalities, the patients in the intervention group underwent more frequent haematological tests than patients in the control group. This could be a source of bias because any treatment and additional attention from the doctor (difference in care) could lead to an improvement in the patients' outcome. ${ }^{43}$ Moreover, Sox $e t a t^{26}$ found that laboratory tests that have no diagnostic value were independent factors of recovery. Finally, a sponsor-related conflict of interest was identified by our analysis as also acknowledged in the Cochrane review. ${ }^{3}$

\section{Specific problems of the study by Fujimoto et al ${ }^{16}$}

In this study, similar to the study of Neri $e t a l,{ }^{14}$ the randomisation process is not described, and a table with the characteristics of the patients in the two groups is not reported. This makes it impossible to determine the balance which is a direct sign of a good randomisation process. Interestingly, only $75 \%$ of the patients included in the intervention group were analysed. The sample size is not sufficient to reach the needed power for the chosen significance levels provided.

\section{Specific problems of the study by Douglass et al ${ }^{17}$}

In this study, similar to the study of Neri $e t a l,{ }^{14}$ the randomisation process is not described. Twenty-three randomised patients were excluded by a committee and by the principal investigator from the final analysis. This results in a loss of power. Additionally, the reasons for the withdrawal of these patients are not explained well enough and conflict of interest cannot be excluded. A power calculation is not reported.

In 2010, the GASTRIC (Global Advanced/Adjuvant Stomach Tumor Research International) Group published a meta-analysis on the same topic as DiazNieto $e t a l^{3}$ and similarly found a benefit of adjuvant CTx for resectable gastric cancer (HR $0.82,95 \%$ CI $(0.76$ to $0.90)) .{ }^{44}$ The authors found a total of 31 eligible trials. After asking for individual patients' data, they obtained data of 17 trials only. Thus, the performed individual patient-level meta-analysis included only 17 of the 31 studies. This meta-analysis has the advantage to be based on individual patient data and has the limitation to include only a part of the existing literature (17 of 31 studies, 55\%). Consequently, the results should be treated with caution because they are only partial.

Generally, the discussion about quality and quality assessment of medical publications is still ongoing. When authoring a clinical study, it is important to describe the study according to the CONSORT checklist ${ }^{22}$ if the study is an RCT, or according to the STROBE (Strengthening the Reporting of Observational Studies in Epidemiology) checklist ${ }^{45}$ if it is observational. In the case of a meta-analysis, it is mandatory to check the validity of each publication and this check should be included in the review. The PRISMA (Preferred Reporting Items for Systematic Reviews and Meta-Analyses) checklist ${ }^{46}$ helps authors to improve the quality of a meta-analysis of RCT while the MOOSE (Meta-analysis of Observational Studies in Epidemiology) guidelines ${ }^{47}$ instruct the process of meta-analysing observational studies. In several medical journals, the checklist that goes with the study type must be submitted together with the main manuscript. This increases the quality and standardisation of publications and it is recommended that this procedure becomes a standard of practice for each journal. Several journals also request the trial registration number to consider a study for publication and this is also recommended to become a standard of practice for all publication avenues.

For a reviewer, it is important to carefully evaluate a publication, in particular when a RCT is reported. Design, conduct, reporting, and statistics should be analysed in detail before acceptance. Only valid studies are reliable studies. For an expert pool aiming to publish guidelines, it is necessary to scrutinise the validity of single studies and of meta-analyses as well. As recently shown by Shnier et $a l^{48}$ financial conflict of interest and relationships between guideline authors and drug companies are common and represent a source of bias in studies. As authoritative value is assigned to guidelines, it is important to develop formal policies to limit the potential influence of any conflict of interest on guideline recommendations. ${ }^{48}$ Only in this way it is possible to improve the quality of medical publications.

In the second part of our work, we performed the meta-analysis first without the four analysed studies and showed that the result of the meta-analysis does not differ from that of the original one. Moreover, when the other four studies with positive and statistically significant results were excluded as well and only 26 statistically non-significant studies were included, we still found a statistically significant meta-analysis estimate confirming the better survival in patients receiving postsurgical CTx in comparison to those undergoing only gastric resection. This is due to the fact that meta-analyses increase power as described in the Cochrane Handbook ${ }^{49}$ : 'many individual studies are too small to detect small effects, but when several are combined there is a higher chance of detecting an effect.' This point is very critical as it means that a statistically significant result in a meta-analysis can be obtained even if none of the included studies found a statistically significant result. This finding again highlights the importance of including only studies of high quality in a meta-analysis, especially in the case of studies which did not find a statistically significant estimate. A meta-analysis can often find a statistically significant result just because of the increase of sample size independently from the quality of the included studies. Yet another example of a meta-analysis with a global statistic positive estimate even if all included studies are not statistically significant can be found in the literature ${ }^{50}$ and is already critically revised. ${ }^{51}$ 


\section{Implications for practice}

Following the results of the Cochrane review, postsurgical CTx should be used for patients with resectable gastric cancer. However, it is important to note that some of the included trials contain limitations so that definitive assessments of this topic should be delayed until future trials are properly developed. The four analysed studies that were chosen because of their attributed weights are not of sufficient validity to be included in a meta-analysis, which holds for most of the other studies included.

Perioperative CTx in patients with gastric cancer is now the standard treatment in most centres today and has found its recommendation in several national guidelines and has also been proposed by a Cochrane review. ${ }^{52}$ However, critical analysis of the leading publications that support perioperative CTx treatment ${ }^{53-55}$ uncovered serious shortcomings particularly with regard to patient selection, changes in protocol, homogeneity of subjects, surgical quality and analysis of the results. ${ }^{56}$ The authors of this critical appraisal conclude that none of these studies justify an unrestrained recommendation of perioperative CTx for advanced gastric cancer. Even more interesting, the same group found different recommendations in international guidelines on this topic, despite the fact that all guidelines claim to be based on the same publications. ${ }^{57}$

Although perioperative CTx in case of advanced gastric cancer is recommended, the literature needs to be reassessed in detail in order to avoid unnecessary side effects for the patients as well as unnecessary costs for the healthcare systems.

Contributors GM, DHB and MK contributed substantially to conception and design of the study. GM and MK contributed to analysis and interpretation of the data and drafted the article. GM performed the meta-analysis. All authors gave the final approval of the version to be published.

Competing interests None declared.

Provenance and peer review Not commissioned; externally peer reviewed.

Open Access This is an Open Access article distributed in accordance with the Creative Commons Attribution Non Commercial (CC BY-NC 4.0) license, which permits others to distribute, remix, adapt, build upon this work non-commercially, and license their derivative works on different terms, provided the original work is properly cited and the use is non-commercial. See: http://creativecommons.org/ licenses/by-nc/4.0/

(C) Article author(s) (or their employer(s) unless otherwise stated in the text of the article) 2017. All rights reserved. No commercial use is permitted unless otherwise expressly granted.

\section{REFERENCES}

1. Ferlay J, Soerjomataram I, Dikshit R, et al. Cancer incidence and mortality worldwide: sources, methods and major patterns in GLOBOCAN 2012. Int J Cancer 2015;136:E359-86.

2. Alberts SR, Cervantes A, van de Velde CJ. Gastric cancer: epidemiology, pathology and treatment. Ann Oncol 2003;14 Suppl 2:31ii-6.

3. Diaz-Nieto R, Orti-Rodriguez R, Winslet M. Post-surgical chemotherapy versus surgery alone for resectable gastric cancer (Review). In: The Cochrane Library, 2013. Issue 9.

4. Nakajima T. Gastric cancer treatment guidelines in Japan. Gastric Cancer 2002:5:1-5.
5. Paoletti X, Oba K, Burzykowski T, et al. Benefit of adjuvant chemotherapy for resectable gastric cancer: a meta-analysis. JAMA 2010;303:1729-37.

6. Di Costanzo F, Gasperoni S, Manzione L, et al. Adjuvant chemotherapy in completely resected gastric cancer: a randomized phase III trial conducted by GOIRC. J Natl Cancer Inst 2008:100:388-98.

7. Hu JK, Chen ZX, Zhou ZG, et al. Intravenous chemotherapy for resected gastric cancer: meta-analysis of randomized controlled trials. World J Gastroenterol 2002;8:1023-8.

8. Earle CC, Maroun JA. Adjuvant chemotherapy after curative resection for gastric cancer in non-Asian patients: revisiting a metaanalysis of randomised trials. Eur J Cancer 1999;35:1059-64.

9. Hermans J, Bonenkamp JJ, Boon MC, et al. Adjuvant therapy after curative resection for gastric cancer: meta-analysis of randomized trials. J Clin Oncol 1993;11:1441-7.

10. Kjaergard LL, Villumsen J, Gluud C. Reported methodologic quality and discrepancies between large and small randomized trials in meta-analyses. Ann Intern Med 2001;135:982-9.

11. Moher D, Pham B, Jones A, et al. Does quality of reports of randomised trials affect estimates of intervention efficacy reported in meta-analyses? Lancet 1998;352:609-13.

12. Schulz KF, Chalmers I, Hayes RJ, et al. Empirical evidence of bias. Dimensions of methodological quality associated with estimates of treatment effects in controlled trials. JAMA 1995;273:408-12.

13. Wood L, Egger M, Gluud LL, et al. Empirical evidence of bias in treatment effect estimates in controlled trials with different interventions and outcomes: meta-epidemiological study. BMJ 2008;336:601-5.

14. Neri B, Cini G, Andreoli F, et al. Randomized trial of adjuvant chemotherapy versus control after curative resection for gastric cancer: 5-year follow-up. Br J Cancer 2001;84:878-80.

15. Sakuramoto S, Sasako M, Yamaguchi T, et al. Adjuvant chemotherapy for gastric cancer with S-1, an oral fluoropyrimidine. N Engl J Med Overseas Ed 2007;357:1810-20.

16. Fujimoto S, Akao T, Itoh B, et al. Protracted oral chemotherapy with fluorinated pyrimidines as an adjuvant to surgical treatment for stomach cancer. Ann Surg 1977;185:462-6.

17. Douglass HO. Controlled trial of adjuvant chemotherapy following curative resection for gastric cancer. The Gastrointestinal Tumor Study Group. Cancer 1982;49:1116-2.

18. Chou FF, Sheen-Chen SM, Liu PP, et al. Adjuvant chemotherapy for resectable gastric cancer: a preliminary report. J Surg Oncol 1994;57:239-42

19. Cirera L, Balil A, Batiste-Alentorn E, et al. Randomized clinical trial of adjuvant mitomycin plus tegafur in patients with resected stage III gastric cancer. J Clin Oncol 1999;17:3810-5.

20. Grau JJ, Estapé J, Alcobendas F, Estape'J AF, et al. Positive results of adjuvant mitomycin- $C$ in resected gastric cancer: a randomised trial on 134 patients. Eur J Cancer 1993;29A:340-2

21. Nakajima T, Kinoshita T, Nashimoto A, et al. Randomized controlled trial of adjuvant uracil-tegafur versus surgery alone for serosa-negative, locally advanced gastric cancer. $\mathrm{Br} J$ Surg 2007;94:1468-76.

22. Moher D, Schulz KF, Altman DG. The CONSORT statement: revised recommendations for improving the quality of reports of parallelgroup randomized trials. Ann Intern Med 2001;134:657-62.

23. Benedetti F, Amanzio M. The neurobiology of placebo analgesia: from endogenous opioids to cholecystokinin. Prog Neurobiol 1997;52:109-25.

24. Buckalew LW, Coffield KE. An investigation of drug expectancy as a function of capsule color and size and preparation form. $J$ Clin Psychopharmacol 1982;2:245-8.

25. Wall PD. Pain and the placebo response. Ciba Found Symp 1993;174:187-216.

26. Sox HC, Margulies I, Sox $\mathrm{CH}$. Psychologically mediated effects of diagnostic tests. Ann Intern Med 1981;95:680-5.

27. Thomas KB. General practice consultations: is there any point in being positive? Br Med J 1987;294:1200-2.

28. Bass MJ, Buck C, Turner L, et al. The physician's actions and the outcome of illness in family practice. J Fam Pract 1986;23:43-7.

29. Gracely RH, Dubner R, Deeter WR, et al. Clinician's expectations influence placebo analgesia. Lancet 1985;1:1-43.

30. Greenfield S, Kaplan S, Ware JE. Expanding patient involvement in care. Effects on patient outcomes. Ann Intern Med 1985;102:520-8.

31. Stewart MA. Effective physician-patient communication and health outcomes: a review. CMAJ 1995;152:1423-33.

32. Waber RL, Shiv B, Carmon Z, et al. Commercial features of placebo and therapeutic efficacy. JAMA 2008;299:1016-7.

33. Porzsolt F, Eisemann M, Habs M, et al. Form follows function: pragmatic controlled trials (PCTs) have to answer different questions 
and require different designs than randomized controlled trials (RCTs). Z Gesundh Wiss 2013;21:307-13.

34. Altman DG, Schulz K. Concealing treatment allocation in randomized trial. BMJ 2001;323:446-7.

35. Neri B, de Leonardis V, Romano S, et al. Adjuvant chemotherapy after gastric resection in node-positive cancer patients: a multicentre randomised study. Br J Cancer 1996;73:549-52.

36. Pocock SJ, Simon R. Sequential treatment assignment with balancing for prognostic factors in the controlled clinical trial. Biometrics 1975;31:103-15.

37. Taves DR. Minimization: a new method of assigning patients to treatment and control groups. Clin Pharmacol Ther 1974;15:443-53.

38. Wei L-J. A class of designs for sequential clinical trials. J Am Stat Assoc 1977;72:382-6.

39. Wei LJ. The adaptive biased coin design for sequential experiments. Ann Stat 1978;6:92-100.

40. Xu Z, Proschan M, Lee S. Validity and power considerations on hypothesis testing under minimization. Stat Med 2016;35:2315-27.

41. Berger VW. Minimization, by its nature, precludes allocation concealment, and invites selection bias. Contemp Clin Trials 2010;31:406.

42. Committee for Proprietary Medicinal Products (CPMP). Committee for Proprietary Medicinal Products (CPMP): points to consider on adjustment for baseline covariates. Stat Med 2004;23:701-9.

43. Koshi EB, Short CA. Placebo theory and its implications for research and clinical practice: a review of the recent literature. Pain Pract 2007;7:4-20.

44. Paoletti X, Oba K, Burzykowski T, et al. Benefit of adjuvant chemotherapy for resectable gastric cancer: a meta-analysis. JAMA 2010;303:1729-37.

45. von Elm E, Altman DG, Egger M, et al. The Strengthening the Reporting of Observational Studies in Epidemiology (STROBE) statement: guidelines for reporting observational studies. Bull World Health Organ 2007;85:867-72.

46. Moher D, Liberati A, Tetzlaff J, et al. Preferred reporting items for systematic reviews and meta-analyses: the PRISMA Statement. Open Med 2009;3:e123-30.

47. Stroup DF, Berlin JA, Morton SC, et al. Meta-analysis of observational studies in epidemiology: a proposal for reporting.
Meta-analysis Of Observational Studies in Epidemiology (MOOSE) group. JAMA 2000;283:2008-12.

48. Shnier A, Lexchin J, Romero M, et al. Reporting of financial conflicts of interest in clinical practice guidelines: a case study analysis of guidelines from the Canadian Medical Association Infobase. BMC Health Serv Res 2016;16:383-90.

49. Higgins JPT, Green S. Cochrane Handbook for Systematic Reviews of Interventions. $2011 \mathrm{http}$ ://handbook.cochrane.org/

50. Akl EA, Kahale LA, Neumann I, et al. Anticoagulation for the initia treatment of venous thromboembolism in patients with cancer. Cochrane Database Syst Rev 2014;6:CD006649.

51. Brögger C. Validity of systematic reviews of the Cochrane Collaboration [Validität von Systemischen Reviews der Cochrane Collaboration]. Faculty of Medicine, University of Ulm, UIm, Germany 2014.

52. Ronellenfitsch U, Schwarzbach M, Hofheinz R, et al. Perioperative chemo(radio)therapy versus primary surgery for resectable adenocarcinoma of the stomach, gastroesophageal junction, and lower esophagus. Cochrane Database Syst Rev 2013:CD008107.

53. Cunningham D, Allum WH, Stenning SP, et al. Perioperative chemotherapy versus surgery alone for resectable gastroesophageal cancer. N Engl J Med 2006;355:11-20.

54. Schuhmacher C, Gretschel S, Lordick F, et al. Neoadjuvant chemotherapy compared with surgery alone for locally advanced cancer of the stomach and cardia: European Organisation for Resarch and Treatment of Cancer randomized trial 40954. J Clin Oncol 2010;28:5210-8.

55. Ychou M, Boige V, Pignon JP, et al. Perioperative chemotherapy compared with surgery alone for resectable gastroesophageal adenocarcinoma: an FNCLCC and FFCD multicenter phase III trial. J Clin Oncol 2011;29:1715-21.

56. Bauer K, Porzsolt F, Henne-Bruns D. Can perioperative chemotherapy for advanced gastric cancer be recommended on the basis of current research? a critical analysis. J Gastric Cancer 2014;14:39-46.

57. Bauer K, Schroeder M, Porzsolt F, et al. Comparison of international guidelines on the accompanying therapy for advanced gastric cancer: reasons for the differences. J Gastric Cancer 2015;15:10-18. 